\title{
MARIO OSORIO MARQUES: EXIGÊNCIAS À FORMAÇÃO E À DOCÊNCIA EM
} SALA DE AULA

\author{
MARIO OSORIO MARQUES: REQUIREMENTS FOR TRAINING AND TEACHING IN A \\ CLASSROOM \\ MARIO OSORIO MARQUES: EXIGENCIAS A LA FORMACIÓN Y LA DOCENCIA EN EL \\ $A U L A$
}

Martin Kuhn

E-mail: martk@outlook.com.br

Universidade Regional Integrada do Alto Uruguai e das Missões (URI - RS)

Mara Lúcia Welter Kuhn

E-mail:maluwka@hotmail.com

Faculdade de Educação e Tecnologia da Região Missioneira (FETREMIS)

\begin{abstract}
RESUMO
Partimos da compreensão que a formação inicial e continuada de professores é a possibilidade de transformação do cotidiano escolar. Nesse sentido, é imperativo ao professor conhecer os fundamentos de sua profissão, saberes e conhecimentos que balizam o trabalho docente. Ao professor cabe conhecer quais as bases epistemológicas que orientam sua prática docente. $\mathrm{O}$ artigo reflete acerca das contribuições de Mario Osorio Marques à compreensão da formação de professores e das práticas educativas de sala de aula. Trata-se de uma reflexão teórico-bibliográfica que busca situar que conhecimentos, saberes e disposições propostas por Marques como exigências para a docência e sua formação. Estrutura-se em dois movimentos: o primeiro abordará a formação do professor/educador a partir da dimensão hermenêutica, da crítico-dialética e da racionalidade epistêmico-instrumental e o segundo movimentos abordará os desdobramentos dessas dimensões na condução das práticas educativas do face a face em sala de aula.
\end{abstract}

PALAVRAS-CHAVE: Formação de professores. Práticas educativas. Mario Osorio Marques

\begin{abstract}
We start from the understanding that the initial and continuous formation of teachers is the possibility of transforming everyday school. In this sense, it is imperative for the teacher to know the fundamentals of his profession, which knowledge that guide the teaching work. The teacher has to know the epistemological bases that guide his teaching practice. The article reflects on the contributions of Mario Osorio Marques to the understanding of teacher training and classroom practices. It is a theoretical-bibliographical reflection that seeks to situate what knowledge and dispositions are proposed by Marques as requirements for teaching and its formation. It is structured in two movements: the first will address the teacher / educator's formation from the hermeneutic, critical-dialectical and epistemic-instrumental rationality dimensions, and the second movement will address the unfolding of these dimensions in the conduct of face-to-face educational practices in the classroom.
\end{abstract}

KEYWORDS: Teacher training. Educational practices. Mario Osorio Marques.

\section{RESUMEN}

Partimos de la comprensión de que la formación inicial y continuada de profesores es la posibilidad de transformación de la cotidianidad escolar. En ese sentido, es imperativo al profesor conocer los fundamentos de su profesión, saberes y conocimientos que balizan el trabajo docente. Al profesor corresponde conocer cuales bases epistemológicas son las que orientan su práctica docente. El articulo reflexiona acerca de las contribuciones de Mario Osorio Marques a la comprensión de la formación de profesores y de las prácticas educativas del aula. Se trata de una reflexión teórico-bibliográfica que busca situar que conocimientos, saberes y disposiciones propuestas por Marques como exigencias para la docencia y su formación. Se Estructura en dos movimientos: El primero abordará la formación del profesorleducador a partir de la dimensión hermenéutica, de la crítico dialéctica y de la racionalidad epistémico-instrumental y el segundo movimiento abordará los despliegues de esas dimensiones en la conducción de las prácticas educativas del cara a cara en el aula.

PALABRAS CLAVE: Formación de profesores. Prácticas educativas. Mario Osorio Marques. 


\section{INTRODUÇÃO}

Mario Osorio Marques nasceu em São Francisco de Paula, Rio Grande do Sul, em 2 de janeiro de 1925. Tornou-se frei capuchinho, conhecido como Frei Matias de São Francisco de Paula. Exerceu a maior parte do seu sacerdócio na cidade de Ijuí (RS), onde constituiu família após o abandono do ministério. Formado em Filosofia e Teologia, fez doutorado em Educação na Universidade Federal do Rio Grande do Sul no ano de 1996, na condição de candidato com notório saber. Em Ijuí foi líder comunitário e professor universitário, constituindo-se no idealizador do ensino superior em Ijuí com a criação da FAFI (Faculdade de Filosofia, Ciências e Letras) no ano de 1957, hoje Universidade Regional do Noroeste do Estado do Rio Grande do Sul - UNIJUÍ. Desde a década de 1980 desenvolveu uma intensa atividade de pesquisador, deixando um legado intelectual de aproximadamente duas dezenas de livros, tratando, especialmente, de temas vinculados à educação. Morreu no ano de 2002, aos 77 anos ${ }^{1}$.

Entre os temas de seu interesse a formação de professores e as práticas educativas diretas do face a face em sala de aula são significativas. Temas que serão aqui explorados. Marques (1990; 1990a), quando se propõe a pensar a formação do pedagogo/professor e a prática educativa nas relações face a face em sala de aula, o faz a partir das três dimensões: a pedagogia enquanto hermenêutica; a pedagogia enquanto crítico-dialética e a pedagogia enquanto racionalidade epistêmico-instrumental. Se as tomarmos em termos de conhecimentos de professor ou de pedagogia ${ }^{2}$, equivale à proposição de uma tipologia de saberes requeridos a quem exerce e para quem pretende exercer a docência. Nesse contexto, significa reconhecer e afirmar, a partir da proposição de Marques, que a identidade do professor pressupõe o domínio de um determinado conjunto de conhecimentos à docência.

Na obra Pedagogia: a ciência do educador (1990a, p. 84), Marques propõe a formação do pedagogo, do educador, partindo do pressuposto que esse necessita dominar um aparato ou conjunto de conhecimentos teóricos e práticos requeridos pelo fenômeno educativo. Assim, em sua tarefa primeira e fundamental, cabe à pedagogia, ciência do educador, "vincular as práticas educativas a uma sólida condução teórica”. Dessa forma, a pedagogia ou a ciência do educador "não é apenas conhecimento $d a$ educação feita ou para a educação a fazer-se, mas conhecimento que se constrói audazmente ao fazer-se a educação e como diretriz, sempre provisória, para as decisões exigidas a cada passo e momento e no interior do próprio processo da educação". (Ibidem, p. 87). É nessa relação que a pedagogia se constitui como ciência do 
educador/pedagogo. É na dialética entre as práticas educativas e a explicitação teórica das mesmas que teoria e prática se constroem e reconstroem. É nesse diálogo com a tradição, com as nossas deliberações acerca da educação, de nossas opções emancipatórias, que se constituem a identidade da escola e do professor.

Assim, para tornar mais nítido o entendimento de Marques (1990) sobre a formação do educador e a compreensão das relações educativas no contexto da sala de aula, referidas as três dimensões, essas serão abordadas a partir de duas questões básicas, como sugere o próprio educador: a) a especificidade do saber do professor/educador; b) a especificidade da prática pedagógica no cenário das relações educativas diretas imediatas ${ }^{3}$, basicamente as relações em sala de aula.

A reflexão em questão é de cunho teórico. Estrutura-se em dois movimentos: o primeiro abordará a formação do professor/educador a partir da dimensão hermenêutica, críticodialética e da racionalidade epistêmico-instrumental e o segundo abordará os desdobramentos dessas dimensões na condução das práticas educativas do face a face pelo professor/educador. Considera-se que a proposição de Marques supera a dicotomia da racionalidade positivistas de caráter acadêmico (SHULMAN, 2005) ${ }^{4}$ e as epistemologias da prática (TARDIF, 2004) $)^{5}$ que têm orientado largamente a formação de professores nas últimas décadas.

\section{A ESPECIFICIDADE DO SABER DO PROFESSOR/EDUCADOR}

Mario Osorio Marques (2000, 1990, 1990a) advoga três saberes como imprescindíveis à formação do educador: a pedagogia enquanto hermenêutica; a pedagogia enquanto críticodialética e a pedagogia enquanto racionalidade epistêmico-instrumental. A reflexão acerca dessas três dimensões, ainda que de modo sucinto, ajuda-nos a compreender o que autor propõe à formação do educador.

Assim, de imediato, é preciso considerar que essas três dimensões da formação do educador articulam estreitamente a relação entre teoria e prática. Pois para ele, por ser uma ação proposital e sistemática, a educação "exige uma tomada de consciência e um direcionamento explícito" e que tal direcionamento requer que ela vá além "daquilo que a intuição prática ou o império dos fatos e circunstâncias prescrevem, e para que não é suficiente a teoria por si só, como se regra universal, válida para qualquer prática”. (MARQUES, 1990, p. 17). Reafirma, dessa forma, os conhecimentos teóricos das ciências da educação e os conhecimentos práticos 
dos profissionais da educação, contudo não mais a partir da ruptura entre teoria e prática predominante na perspectiva da formação acadêmica ${ }^{6}$ do professor, tampouco das variadas denominações da epistemologia da prática ${ }^{7}$. Nesse sentido, as três dimensões que se seguem assentam-se no diálogo entre a teoria e prática e prática e teoria ou na práxis, como propõe o autor.

Sob essa compreensão, Marques (1990a, p. 83) produz uma crítica consistente às perspectivas de educação e de formação do pedagogo/educador constituídas a partir de uma colcha de retalhos e de um "repertório de conhecimentos especializados adquiridos e aplicados por um generalista não-especializado". E ainda mais, contexto em que a formação do educador fica "à mercê de enfoques desencontrados e insuficientemente aprofundados, ou a mercê ora do psicologismo, ora do sociologismo, ora das fontes de estimulação orgânica ou ambiental, etc.”. (Ibidem, p. 83). Assim, o diálogo da hermenêutica e da teoria crítica - modelo reconstrutivo habermasiano - dão lastro as suas reflexões sobre a educação, à formação do educador e às práticas educativas de sala de aula e dessas opções teórico-práticas emergem as dimensões teórico-práticas da formação/atuação do professor.

A primeira exigência proposta por Marques (1990a, p. 93) à formação do pedagogo/educador é a dimensão hermenêutica. "Em contraposição ao objetivismo científico e à imparcialidade metodológica baseada na oposição homem e mundo, sujeito e objeto, a hermenêutica considera o homem como ser-no-mundo". Ainda mais, um "sujeito que determina o mundo e é por ele determinado, já que sempre inserido no mundo e condicionado por seu contexto de experiências, pela tradição cultural e pelo conjunto de estruturas da comunidade em que vive". (Ibidem, p. 93). Essa dimensão reconhece a historicidade e temporalidade das práticas educativas.

Assim, essa primeira exigência, a dimensão hermenêutica, "procura penetrar no tempo da educação para desvendar-lhe o sentido histórico. (...) Trata-se de um 'refazer para trás' do processo pelo qual se sedimentaram os sentidos que agem na subjetividade presente e as condições materiais que os sustentam”. (MARQUES, 1990, p. 18). Trata-se de escavar os sedimentos que se acumularam ao longo de nossa história da educação, da formação de professores e das práticas educativas. Mais do que isso, desvelar o que se encobriu no tempo, oportunizando que se compreenda a concretude de nossa realidade educativa. Essa tradição pode nos ajudar a interpretar as novas questões e desafios que a realidade apresenta. 


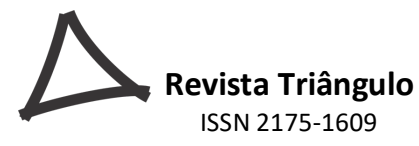

De mais a mais, a hermenêutica se realiza na tradução/compreensão. Concretiza-se à medida que abre a possibilidade de conversar com a tradição, não tanto no sentido de restituir a origem dos significados dos conhecimentos, dos saberes e dos valores, mas de "reconstruílos em seu sentido de agora, em sua capacidade de ainda fazer história, em suas influências sobre as gerações posteriores, em nossa em especial”. (MARQUES, 1990a, p. 94). Permite, conforme o autor, "produzir a significação efetivadora e atualizadora da consciência histórica na fusão dos horizontes do passado e do presente como alteridade no horizonte maior e móvel da história efetual, ou histórias dos efeitos que se atualizam”. (Ibidem, p. 94).

Sedimentação parece-nos um bom termo para se referir à síntese histórica, que não é síntese no sentido de conclusão lógica, mas no sentido de abertura que se funda no passado, na tradição, para pensar sempre de modo novo a tarefa educativa no presente. Refazer para trás não para simplesmente reproduzir, mas recriar criativamente o presente. Subentende-se que todo aquele que pretende ser professor necessita conhecer em profundidade a pedagogia, pois do conhecer dessa historicidade sedimentada emergem possibilidades para pensar os desafios que o processo cotidiano do educar apresenta.

Assim, a hermenêutica permite ler os indícios manifestos ou presentes nas diferentes concepções de formação do professor, bem como aquilo que está sedimentado em sua prática. A tradição, a história e a linguagem marcaram e marcam a identidade do professor, mas enquanto agora, na presentificação, permitem também reelaborá-la. Nesse sentido, há impossibilidade de conhecer-se fora desses horizontes do mundo social. Flickinger (2010, p. 157), afirma que esses horizontes representam o "contexto indispensável a qualquer tentativa de conhecer". Reitera que a "hermenêutica parte do pressuposto que toma como ponto de partida a impossibilidade de o sujeito conhecedor colocar-se fora desse seu contexto querendo distanciar-se dele, a fim de dominá-lo". Por isso, cabe à formação assegurar o mergulho no tempo da educação para desvendar-lhe o sentido histórico ou, como afirma Marques (1990), "refazer para trás" para compreender o que está sedimentado para reelaborá-lo e presentificálo. Essa é a tarefa da pedagogia enquanto hermenêutica.

A pedagogia enquanto crítico-dialética ou a segunda exigência à formação de do pedagogo/educador busca romper com o "sentido dado na facticidade, para estabelecê-lo no horizonte das possibilidades abertas à ação comunicativa, fundada na participação livre e igual de todos os envolvidos no processo da educação”. (MARQUES, 1990, p. 19). Inscreve-se, neste sentido, a prática educativa "como exigência fundante de práxis humana o reconhecimento 
universal de todos os homens em sua dignidade inalienável no horizonte da efetivação de um sentido radical: o sentido da emancipação humana". (Idem, 1990a, p. 95). Trata-se fundamentalmente dos sentidos que queremos imprimir à formação de professores, bem como, às práticas educativas.

Assim, se hermenêutica busca interpretar ou tornar presente os sentidos assumidos pela educação em nossa tradição, a dimensão crítica busca descortinar os seus rumos, "o plano crítico do sentido radical da emancipação humana”. (MARQUES, 1990a, p. 105). Conforme o educador, significa antecipar teoricamente os sentidos da tarefa educativa, ou seja, trata-se da "revelação do sentido último da educação pelo processo reflexivo em que se produzam o esclarecimento e a emancipação, passando do mundo das coisas com que nos deparamos, "daquilo que é", para "o que deve ser".

A exigência crítico-dialética da Pedagogia ou da formação do educador volta-se à compreensão e definição dos sentidos que queremos atribuir à educação enquanto projeto coletivamente definido. Trata-se de deliberar acerca das intencionalidades que queremos, que humanos, que sociedade, que educação, que convicções, que afetos, que motivações, que interesses e que valores esperamos que constituam as referências formativas dos nossos espaços educativos. Significa assumir uma posição político-ideológica, um determinado conjunto de pressupostos que orientarão a perspectiva da formação humana.

Trata-se em última instância que a formação do educador esteja fundada na compreensão de que a vida social "esteja presidida pelo interesse geral" vinculada "a adoção das decisões relevantes ao princípio da discussão geral livre da dominação, sob a base exclusiva da autoridade do melhor argumento". (MARQUES, 1990a, p. 151). Reafirma-se a comunicação, o diálogo argumentativo como princípio regulador e critério de toda crítica e afirmação de nossas escolhas. Não se trata de definir de modo definitivo e absoluto as nossas escolhas e deliberações, como pondera Stein (1986), mas reconhecendo-as como provisórias e possíveis de serem abandonadas.

Nesse sentido, a exigência crítico-dialética da pedagogia ou da formação do educador tem uma meta ambiciosa, ou seja, a transformação da sociedade. Significa pôr em xeque o predomínio da racionalidade instrumental como ordem de nossa realidade. Para Hermann (1994, p. 100), tal opção requer que a formação do educador assuma uma postura críticodialógica e que compete à educação a "vinculação a um projeto emancipatório". O que só é 
possível pela práxis, pela articulação entre as proposições teóricas e sua realização no âmbito da prática.

A terceira exigência da formação do educador ou da pedagogia enquanto racionalidade epistêmico-instrumental revisita o que a humanidade já acumulou em termos de conhecimentos sobre a docência e as práticas educativas. Conforme Marques (1990a, p.107)

1) seja dos conteúdos do saber que devem ser criticamente avaliados, selecionados/priorizados, ordenados e graduados, para que se façam orgânicos e adquiram o real sentido com que se inscrevem na ação proposital do ensino/aprendizagem; 2) seja do currículo oculto nas formas em que são trabalhados os conteúdos, e nas normas, valores e crenças; 3) seja dos procedimentos didáticos, das tecnologias desenvolvidas, dos materiais do ensino/aprendizagem, para que se façam fundados no estado atual do desenvolvimento das ciências concernidas e se inscrevam na ação proposital presidida pela prática pedagógica.

O percurso formativo do pedagogo/educador tem por tarefa acessar o que a humanidade produziu de relevante nas diferentes áreas, das disciplinas do conhecimento, dos conteúdos, de currículo, de procedimentos e tecnologias educativas, pois serão inerentes as suas práticas educativas. Para além disso, cabe à formação assegurar a compreensão dos diferentes métodos, metodologias, técnicas e processos de ensino e aprendizagem sempre referidos à formação humana, para o esclarecimento e emancipação. A dimensão epistêmico-instrumental alinhada com as dimensões crítico-reflexiva e hermenêutica imprime outra perpectiva à formação dos educadores e à prática educativa não mais reduzida à compreensão estreita da racionalidade produtiva, técnica e utilitária ou como diria Flickinger (2010, p. 180) não mais guiada pelas "diretrizes da racionalidade econômica".

Assim, as três exigências propostas por Marques buscam assegurar uma formação intelectual criadora, reflexiva, inconclusa, dinâmica, etc. Significa assumir a formação como espaço e tempo contínuo de aprender a profisssionalidade da profisssão. Assim, "Ao assumir o exercício autônomo da profissão, o profissional não interrompe seu período de formação, antes o retoma em novas bases, em desafios outros e em nível de mais estreita vinculação entre prática e teoria". (MARQUES, 1990a, p. 56). Assim, as três dimensões apontam para a superação da racionalidade instrumental, perspectiva científica/técnica e epistemologia da prática, que tem orientado em larga medida a formação de professores.

\section{A ESPECIFICIDADE DA PRÁTICA EDUCATIVA EM SALA DE AULA}


É nas relações educativas do face a face da sala de aula que se realiza o encontro entre a exigência hermenêutica, a crítico-reflexiva e a epistêmico-instrumental do professor. Não somente para compreender e traduzir as relações educativas diretas, mas também para pensálas de modo mais pertinente. Assim, Marques (1990, p. 20) compreende, dessa forma, "que o ponto de partida e o ponto e chegada da pedagogia são as relações educativas em que se defrontam educadores e educandos na imediatez ${ }^{8}$ de práticas concretas determinadas".

A exigência hermenêutica da pedagogia, no âmbito da tradução das práticas educativas diretas da sala, volta-se "a leitura do mundo da sala de aula, para que nele se desvelem os muitos sentidos que nele atuam e se percebam na unidade em que se constituem". (MARQUES, 1990, p. 21). Trata-se da leitura dos mundos que no pequeno mundo da sala de aulas se manifestam, interagem e a fazem existir. Por seu caráter institucional, cabe a pedagogia e ao professor, enquanto prática educativa da sala de aula pensá-la e interrogá-la de modo sistemático, uma vez que se trata de uma prática coletiva, pública, destinada a formação de sujeitos para o espaço público.

O olhar hermenêutico para a sala de aula se apresenta como possibilidade de dialogar com o mundo, com a tradição, com o instituído, com o naturalizado, pois dessa forma, é possível desvelar, ainda que permaneçam sempre veladas, dimensões dos muitos sentidos da prática educativa direta manifesta, o que permite produzi-las de modo sempre atualizado. Mas o que cabe ao professor/educador ler no âmbito da sala de aula? Para Marques (1990, p. 23), "tratase de revelar e despertar o movimento real do mundo vivido, da cultura, das ciências e das artes, na reconstrução racional do que se faz presente em sala de aula, quer em termos de conteúdos ocultos, quer em termos de propósitos explicitados". E como se procede a isso? Pela "reconstrução no sentido de desmontagem e recomposição em modo novo, de maneira hermenêutica, isto é, em obediência à lógica da livre conversação, mais do que a regras préfixadas".

Portanto, a hermenêutica no âmbito da sala de aula não trata simplesmente de traduzir o que se manifesta no âmbito das relações intersubjetivas da sala de aula, mas mais do que isso, implica significá-las de um modo novo. Assim, mais do que meramente interpretação/compreensão, ainda que crítica, significa também sua transformação. A hermenêutica, dessa forma, proporciona a transparência possível dos diversos sentidos que se 


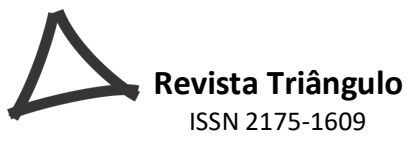

manifestam na sala de aula. Como diria Heidegger (2002), é tornar manifestos fenômenos não descobertos ou ainda desvelar fenômenos entulhados ao longo de uma tradição.

A exigência crítico-reflexiva da Pedagogia nas relações educativas do face a face em sala aula assume a proposições da teoria crítica. Se a hermenêutica busca os sentidos contidos nas relações intersubjetivas da sala de aula, aquilo que está sedimentado, não descoberto ou entulhado, o que para Marques (1990, p. 23) não é suficiente, requer que se faça necessária a busca do "sentido que se queira imprimir às próprias ações, (...) em sentido último da educação pelo processo reflexivo em que se produzam o esclarecimento e a emancipação".

Nesse sentido, a ação educativa direta da sala de aula está lincada a um projeto de emancipação humana, ou seja, de transformação das condições de dominação, como apontam Prestes (1994) e Pucci (1994). Assim, “O sentido radical da educação emancipatória realiza-se no enfrentamento prático da questão dos valores e da questão da coordenação dos planos para a ação coletiva, da formação da vontade política”. (MARQUES, 1990, p. 23). Interroga acerca do sentido do ato educativo das relações educativas diretas.

Em sua exigência instrumental, incumbe à pedagogia das relações educativas diretas da sala de aula, conforme Marques (1990, p. 27)

[...] assumir as contribuições da racionalidade epistêmico-instrumental: a) no que se refere aos saberes e técnicas do mundo da vida na esfera da cultura local (de modo especial, de como nele vivem os educadores sua cultura), da cultura específica de cada faixa etária; b) no que se refere ao patrimônio do saber desenvolvido no estado atual das ciências cujos conteúdos são trabalhados pelas disciplinas do ensino; c) no que se refere às ciências que tratam das condições (biológicas, psíquicas, sociais, etc.) da educação, às tecnologias educacionais apropriadas, aos procedimentos regulados, à didática e às metodologias específicas, aos materiais instrucionais.

Marques (1990, p. 27), quando se refere, por exemplo, aos conteúdos da docência, não os reduz a instrumentos a serem ensinados, mas busca vê-los em sua historicidade, importando, também, a “compreensão crítica deles". Acrescenta a essa reflexão crítica "uma re-leitura hermenêutica dos conteúdos, pela qual, somente, a ciência se converte em fator social da vida humana, isto é, pela tradução das informações científicas relevantes, para a linguagem do mundo da vida". Compreender a intencionalidade presente nesses conteúdos é desconstruí-los. Dessa forma, não se trata somente da compreensão crítica dos conteúdos e de sua re-leitura hermenêutica, cabe à pedagogia também, conforme o autor, "estabelecer os critérios da seleção/priorização e de ordenação/seriação e graduação dos conteúdos para que se façam 
orgânicos, isto é, expressão viva do que acontece no processo do ensino-aprendizagem". (Ibidem, p. 27).

Aos conteúdos, organização, seleção, ordenação e graduação, soma-se a necessidade de pensar os "procedimentos didáticos, das metodologias e técnicas exigidas pelo processo do ensino-aprendizagem”. (MARQUES, 1990, p. 28). Cabe, igualmente, à “pedagogia indagar se os materiais didáticos empregados para subsídio do processo do ensino-aprendizagem são adequados, quer aos objetivos a que devem servir quer às características e exigências do que deles se irão utilizar". (Ibidem, p. 28). Dessa forma, mais do que simplesmente o domínio dos conteúdos, interessa que se agregue a esse o seu entendimento, a possibilidade de redimensionálos e direcioná-los aos interesses práticos da emancipação dos alunos. A isso agrega o entendimento de que os conteúdos consensualmente construídos e validados sejam vivenciados e aplicados. (MARQUES, 1995).

Em síntese, o ponto de partida e de chegada da pedagogia são as relações educativas diretas da sala de aula. "Aí estão os problemas, as questões e, igualmente, as respostas e soluções. Importa assumamos os professores a nova identidade de lúcidos responsáveis pela organização e consolidação das relações educativas”. (MARQUES, 1990, p. 29). Desse modo, é no âmbito das práticas educativas diretas que finalmente se realiza o encontro da pedagogia em sua dimensão hermenêutica, crítico-dialética e a epistêmico-instrumental, âmbito das especulações teóricas, com o cotidiano da escola, da sala de aula e da tarefa do professor, âmbito da pedagogia em sua prática educativa. Ou seja, o tradicional nó do distanciamento da relação teoria e prática, da perspectiva acadêmica e da epistemologia da prática, encontra um razoável encaminhamento.

\section{A CONSIDERAR}

Não com a intenção de atribuir uma tipologia de conhecimentos de professor, tal como propõe Shulman (2005) ou Tardif (2004), mas é inevitável perceber em Marques (1990, 1990a), como anteriormente já referido, um conjunto de conhecimentos como requisitos ao pedagogo/educador. Assume, em nosso entender, uma perspectiva alargada, se comparada com a perspectiva acadêmica ou com as variações da epistemologia da prática. A dimensão hermenêutica, a dimensão critíco-reflexiva e a dimensão instrumental acabam constituindo, 
assim, um repertório de conhecimentos imprescindíveis à formação do pedagogo/educador, bem como atributos à tradução das práticas educativas diretas da sala de aula.

Assim, esse conjunto de conhecimentos e saberes exigentes à profissão de professor constituem, portanto, exigências à sua formação, e são também o suporte interpretativo e compreensivo da tarefa docente em sala de aula. A hermenêutica, à medida que auxilia a penetrar nos tempos transcorridos da educação para desvelar-lhe os muitos sentidos assumidos ao longo da história, permite que o pedagogo se aproprie dos conhecimentos sedimentados na tradição e compreenda o que se manifesta no movimento da sala de aula em termos de ciência, cultura, arte, sujeitos, etc., e possa fazê-lo de modo novo, recriado, criativo.

A dimensão crítico-reflexiva estabelece e esclarece o horizonte de sentido da prática educativa do educador, aqui compreendida como uma educação para o esclarecimento e emancipação, como refere o próprio Marques (1990). Que ser humano queremos formar, que sociedade queremos construir, que pressupostos éticos/morais e estéticos vão orientar as nossas ações, são exigências que carecem ser discutidas em nossas escolas, entre os professores e juntamente com os alunos e seus pais. Trata-se de assumir o compromisso com uma educação com vistas à transformação da sociedade, a construção de um mundo comum democrático, livre, com justiça social, etc.

Por sua vez, a dimensão epistêmico-instrumental assegura o suporte do conhecimento específico da área, da disciplina, dos conteúdos, do currículo, dos fundamentos didáticos e pedagógicos do professor e, igualmente, das metodologias, dos processos de ensino e aprendizagem, etc. Não há prática educativa que possa prescindir da reflexão em profundidade desses requisitos da pedagogia.. Reiteramos que uma educação de qualidade social pressupõe, por parte dos educadores, uma sólida formação epistêmico-instrumental.

Entendemos que as opções teóricas de Marques (1990, 1990a), do diálogo da Hermenêutica e da Teoria Crítica - teoria da ação comunicativa de Habermas -, inscrevem a formação de professores e as práticas educativas em um novo quadro compreensivo. Essas são compreendidas como construção histórica, social, dinâmica, intersubjetiva, que requer o protagonismo de seus atores/educadores/estudantes. Dessa forma, as suas proposições rompem com a racionalidade instrumental e técnica fortemente enraizada e presente em nossa formação de professores e em nossas práticas educativas. 


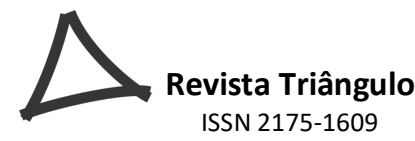

ISSN 2175-1609

Notas

${ }^{1}$ Para maiores detalhes consultar o Artigo: Mario Osorio Marques: breve biografia de um pensador da educação de autoria de José Pedro Boufleuer e Ricardo Rezer.

${ }^{2}$ Marques (1990a, p. 52) compreende "a pedagogia como uma meta-educação, isto é, como discurso sobre a educação e como organização e condução do processo educativo". Para o autor, a pedagogia é a ciência do educador, portanto, a todo professor cabe a tarefa de ser conhecedor da pedagogia à medida que se assume a prática educativa. Para Jean Houssaye (2004, p. 10), “a pedagogia é a reunião mútua e dialética da teoria e da prática educativas pela mesma pessoa, em uma mesma pessoa, o pedagogo é antes de mais nada um prático-teórico da ação educativa". Nesse sentido, dissolve-se, no entender de Libâneo (2003, p. 21), "a designação "pedagogia" para identificar apenas o curso de formação de professores para as séries iniciais do ensino fundamental". Essa compreensão mais alargada de pedagogia é o sentido que nos acompanho no texto.

${ }^{3}$ Entendemos que quando Marques se refere a "relações educativas diretas imediatas" reporta-se a relação face a face educador e educando, já que para ele toda relação educativa se dá em contexto de ação regulamentado entre sujeitos de ação com crenças antecipadoras e interesses diversos. A relação educativa é sempre uma relação mediata, em que professor e alunos conversam sobre o mundo.

4 As categorias de base de conhecimentos para o ensino propostas por Shulman (2005, p. 10), incluiriam: "conocimiento del contenido; conocimiento didáctico general, teniendo en cuenta especialmente aquellos principios y estrategias generales de manejo y organización de la clase que trascienden el ámbito de la asignatura; conocimiento del currículo, con un especial dominio de los materiales y los programas que sirven como "herramientas para el oficio" del docente; conocimiento didáctico del contenido: esa especial amalgama entre materia y pedagogía que constituye una esfera exclusiva de los maestros, su propia forma especial de comprensión profesional; conocimiento de los alumnos y de sus características; conocimiento de los contextos educativos, que abarcan desde el funcionamiento del grupo o de la clase, la gestión y financiación de los distritos escolares, hasta el carácter de las comunidades y culturas; y conocimiento de los objetivos, las finalidades y los valores educativos, $y$ de sus fundamentos filosóficos e históricos".

${ }^{5}$ A tipologia de Tardif (2004) é constituída a partir de 4 saberes: formação profissional, disciplinar, curricular e da experiência. Os saberes da formação profissional são os "transmitidos por las instituciones de formación del profesorado (Escuelas de Magisterio ou Facultades de Ciencias de la Educación)" (p. 30); os saberes disciplinares são os dispostos pela "nuestra sociedad que corresponden a los diversos campos del conocimiento, en forma de disciplinas, dentro de las distintas facultades y cursos. Los saberes disciplinarios (por ejemplo, matemáticas, historia, literatura, etc.) (p. 30). Os saberes curriculares que "corresponden con los discursos, objetivos, contenidos y métodos a partir de los cuales la instituición escolar categoriza y apresenta los saberes sociales que ella misma define y selecciona como modelos de la cultura erudita y de formación para esa cultura" (p.30); e os saberes da experiência que são os saberes que "brotan de la experiencia, que se encarga de validarlos. Se incorporan a la experiencia individual y colectiva em forma de hábitos y habilidades, de saber hacer y de saber ser" (p. 31).

${ }^{6} \mathrm{O}$ que se pode afirmar a partir dessa perspectiva, conhecida como universitária, acadêmica, disciplinar, é que essa tem predominado na formação de professores. Para Shulman (2004), em ensino, Knowledge base é o corpo de compreensões, conhecimentos, habilidades e disposições de que um professor necessita para atuar efetivamente numa dada situação de ensino". (apud ALMEIDA; BIAJONE, 2007, p. 283). Tardif (2004, p. 19) ao criticar essa perspectiva afirma que se trata de um formação de professores centrada nos "conocimientos disciplinares, producidos, por regla general, en una redoma de vidrio, sin conexión alguna con la acción professional, debiendo aplicarse, a continuación, en concreto, por médio de prácticas u de otras atividades de este gênero".

${ }^{7}$ Para Tardif, a epistemologia da prática busca investigar e construir uma tipologia de saberes docentes, emergentes e relevantes a partir da prática cotidiana do professor. Dessa forma, afirma que os saberes docentes necessitam ser compreendidos em sua "íntima relación con su trabajo en la escuela y en el aula". Mesmo que os professores utilizem diferentes saberes "en función de su trabajo y de las situaciones, condicionamentos y recursos ligados a esa responsabilidade. En suma, el saber está al servicio del trabajo”. (TARDIF, 2004, p. 14). 
${ }^{8}$ Entenda-se aqui imediatez como relações face a face entre educador e educando, sempre mediadas pelos contextos sociais, políticos, econômicos, culturais, etc. Portanto, não se tratam de relações imediatas, mas sempre mediadas.

\section{REFERÊNCIAS}

ALMEIDA, Patrícia C. A. de; BIAJONE, Jefferson. Saberes docentes e formação inicial de professores: implicações e desafios para as propostas de formação. In: Educação e Pesquisa. São Paulo, v.33, n.2, maio/ago. 2007. p. 281-295

BOUFLEUER, J. P.; REZER, R. Mario osorio marques: breve biografia de um pensador da educação. Revista Pedagógica, Chapecó, v. 18, n. 37, jan./abr. 2016. p. 15-27. Disponível em: https://bell.unochapeco.edu.br/revistas/index.php/pedagogica/article/view/3164/1817 Acesso em: 08-01-2018.

FLICKINGER, Hans-Georg. A caminho de uma pedagogia hermenêutica. São Paulo: Autores Associados, 2010.

HEIDEGGER, Martin. Ser e tempo. Rio de Janeiro: Editora Vozes, 2002.

HOUSSAYE, Jean. et al. Manifesto a favor dos pedagogos. Porto Alegre: Artmed, 2004.

LIBÂNEO, José C. O debate sobre o estudo científico da educação: ciência pedagógica ou ciências da educação? Revista Espaço Pedagógico. Passo Fundo, v. 10, n. 15, 2003. p.11-33.

MARQUES, Mario Osorio. A formação do profissional da educação. 3. ed. Ijuí: Editora Unijuí, 2000. Unijuí, 1995.

A aprendizagem na mediação social do aprendido e da docência. Ijuí: Editora Pedagogia: a ciência do educador. Ijuí: Unijuí, 1990a.

. O educador/pedagogo na relação educativa direta. In: Contexto e educação, Ijuí, Livraria Unijuí editora, v. 1, n. 1, jan./mar. 1990. p. 17-30

PRESTES, Nadja Hermann. A razão, a teoria crítica e a educação. In: PUCCI, Bruno (Org.). Teoria crítica e educação. Rio de Janeiro: Vozes, 1994.

PUCCI, Bruno. Teoria crítica e educação. In: PUCCI, Bruno (Org.). Teoria crítica e educação. Rio de Janeiro: Vozes, 1994.

SHULMAN, Lee S. Conocimiento y enseñanza: fundamentos de la nueva reforma. Revista de currículum y formación del professorado, Espanha, Universidad de Granada, v. 9, n. 2, 2005. Disponível em http://www.redalyc.org/articulo.oa?id=56790202. Acesso: 02-03-2015. 
TARDIF, Maurice. Los saberes del docente y su desarrollo profesional. 3. ed. Madrid: Narcea, 2004.

\begin{tabular}{|l|r|}
\hline & Recebido em: 31 Jan. 2018 \\
\hline & Aprovado em: 18 Abr. 2019 \\
\hline
\end{tabular}

